\title{
Analysis on the Barriers and Countermeasures of Internationalization of Young Teachers in Chinese Universities*
}

\author{
Xiaojuan Hui \\ Nankai University Binhai College \\ Tianjin, China
}

\author{
Chao Huang \\ Nankai University Binhai College \\ Tianjin, China
}

\author{
Beibei Yang \\ Nankai University Binhai College \\ Tianjin, China
}

\begin{abstract}
The internationalization of teachers should pay more attention to the domestic internationalization of native teachers. Based on this, the barriers of internationalization of teachers are summarized, including five major obstacles of the cognitive error at organizational level, the deviation of value orientation, the system defects, and the deficiency of teacher's personal motivation and learning cost burden. Correspondingly, the author puts forward five countermeasures, including the functions of positioning the colleges and universities scientifically, giving play to the leading role of teachers, establishing and perfecting management system, developing international organizations and strengthening teachers' academic professional training and education.
\end{abstract}

Keywords-university internationalization; teacher internationalization; the barriers of internationalization; the countermeasures of internationalization

\section{INTRODUCTION}

The internationalization of colleges and universities is not only the concept of history, but also the modern concept, and the concept of development. As early as in the middle ages of college days, the international flow and exchange of students and scholars were very common. And it did not significantly decline until the 15 th century. In the second half of the 20th century, the internationalization of colleges and universities reemerged again. The continuously integrated world economy, the increasingly strengthened international academic network and the ever-changing information technology have propelled different types of higher education institutions to be in the global relationship spectrum of the world. And the internationalization must be a global trend faced by colleges and universities [1]. In the continuous development of the construction of

*CLC number: G451 Article identification code: A

Project Name: Research on the Barriers and Countermeasures of the Internationalization of Young Teachers in Universities and Colleges

Planning Project of Education and Science in Tianjin, No: HE4032 internationalization, more and more scholars and administrators of the colleges and universities realize that teachers are the main body and core of university internationalization. Teachers' participation has become an important condition for university internationalization [2]. In 2008, at the annual meeting of the American Society of Education, some scholars criticized that the higher education in the United States cultivated twenty-first-century students with the facilities of the twentieth century and the teachers of the nineteenth century [3]. It has pointed out the problems of American higher education with the irony. Then, it reminds us that the cultivation and promotion of teachers' capabilities play an important role in higher education. Similarly, teachers play an important role in the construction of the internationalization of colleges and universities. For this reason, many scholars devote themselves to studying the internationalization development of the teachers of colleges and universities. However, most of the existing researches focus on the construction of internationalization of the faculty (focusing on the introduction of teachers) [4] or teachers' cross-border training [5]. While, there are a few researches on the "domestic internationalization" of native teachers. There is no doubt that internationalization is a way and not a purpose. The ultimate goal of internationalization should be to improve the quality of education and international influence of colleges and universities. As the largest group in colleges and universities, the improvement of the internationalization ability of native teachers can effectively promote the quality and influence of the education of colleges and universities. This study focuses on the issue of the internationalization of native teachers. It tries to sort out the barriers of internationalization of native teachers and put forward corresponding solutions to overcome these problems, which are beneficial to the internationalization of higher education, especially the improvement of teachers' abilities and the improvement of educational quality. 


\section{ANALYSIS ON THE BARRIERS OF \\ INTERNATIONALIZATION DEVELOPMENT OF YOUNG TEACHERS OF COLLEGES AND UNIVERSITIES}

A. Cognitive Error: Internationalization of "Teachers" and "Teaching Staff"

The internationalization of teachers and internationalization of teaching staff are significantly different. The internationalization of teachers is oriented to the requirements for development of teachers. And it promotes the internationalization of colleges and universities through the development of teachers. And it pays more attention to the issues of "domestic internationalization" of native teachers. And the internationalization of the teaching staff is concerned about the entire teacher group of the whole university. It pays more attention to the overall internationalization of faculty. The internationalization of the teaching staff focuses on the introduction of teachers with cross-border education and native teachers who are seeking cross-border education. The cost is expensive, and the benefits are not obvious. At the same time, the native teachers are the core groups of the colleges and universities. It also neglects the development of native teachers' ability. In Li Bihong's opinion, the internationalization of teachers in China has received sufficient attention. However, it focuses on introducing talents and cross-border education. And the understanding of the internationalization of native teachers' ability and resource allocation is insufficient [6]. It is not only true at home, but also in many foreign universities. For example, some researches show that the internationalization strategies of British universities mainly focus on the number of international students, and they neglect the internal human resource capacity [7]. A number of studies abroad show that teachers are the key to the success of internationalization strategy [8], and teachers are the engines that drive the internationalization of universities [9]. The American Association for Academic Career Transformation believes that the international development of the colleges and universities does not lie in its size and budget. And it should pay more attention to the ability and participation of native teachers [10]. Foreign researches on the internationalization of teachers have been separated from the internationalization of higher education. And these researches pay more attention to the teachers. These researches aim at promoting the teachers' development through the internationalization of ideas and cultivation. And finally, it has increased the overall internationalization of higher education. Sorcinelli [11], Finkelstein [12] and other scholars focus their research on the internationalization of teachers. We can't treat the internationalization of teachers and the internationalization of faculty equivalently. We can't transfer our attention from the improvement of the internationalization ability of native teachers promoting the domestic internationalization to the introduction of foreign teachers and the cross-border training of native teachers. Otherwise, it would seriously affect the international development of this huge and core group of native teachers. And it has become a significant barrier of the internationalization of teachers.

\section{B. The Deviation of Value Orientation: the Importance of "Data" Is Higher than That of Teachers}

This almost goes in fashion consistent with the higher attention to the internationalization of faculty members than that of the internationalization of teachers. It goes without saying that the ability and level of teachers are the foundation for the development of colleges and universities. Any activity carried out by universities should focus on the development of teachers. And the internationalization activities would have no exception. The ultimate goal of university internationalization should be to promote the development of teachers. And then, it can improve the development of the internationalization of schools through the development of teachers rather than accomplish the goal of internationalization that only cares about data. In China, when it comes to the internationalization, the most common cognition is the internationalization at the indicator level, such as the proportion of international students and the proportion of international teachers. These indicators even become the common indicator for measuring the internationalization of colleges and universities in the rankings of universities. In fact, it is too superficial to understand the internationalization. The internationalization should be a mechanism of the university. And the internationalization is a platform of the colleges and universities to provide students and teachers with opportunities to integrate international resources and to participate in international learning and research. Many internationalization indicators are just logical outcome of the development of the internationalization rather than the goal that is pursued. If the internationalization policies and measures of the colleges and universities only focus on the improvement of international related data, it will seriously violate the original intention of the internationalization. For example, nowadays many colleges and universities attach the importance to the assessment of professional titles and teachers' cross-border education. And even, whether there is any experience of studying abroad or the duration of further studies has become one of the mandatory conditions for the assessment of titles. The so-called international academic exchange based on this goal is difficult to achieve satisfactory results. In addition, the internationalization of the output of scientific research is easy to be investigated and quantized. And the relevant policies of universities are also concentrated on the incentives in this field. And then, it would not only make the teachers focus on the number of papers published in foreign databases, but also neglect the internationalization of curriculum teaching that is difficult to quantify. From the national level, it also makes a great deal of domestic outstanding research results outflow. The studies of Association of International University points out that compared with developed countries, developing countries have paid more attention to scientific internationalization [13]. According the investigation, Li Bihong, et al. find that research activities are still the major international activities for the teachers of the universities in China. However, there are fewer international activities in teaching, and many teachers even have confined their internationalization activities to the internationalization of scientific researches [14]. With the deviation of the value orientation, the teachers 
become the regulated enforcer in the internationalization development strategy of the colleges and universities. The teachers are passive in the international participation. Due to the systematic pressure caused by the deviation of value orientation, it is difficult to promote the transformation of the concepts, thinking and abilities of the teachers. And then, it would reduce the effectiveness of the internationalization of teachers.

\section{The System Defects: the System Construction Isn't Realistic}

There are great differences among the colleges and universities in terms of international competitiveness, resources base and so on. Therefore, the colleges and universities should build an institutional system suitable for their own international development according to their actual conditions. However, this is not the fact. In the process of building an internationalized system, many colleges and universities try to learn from and imitate the relevant systems of the institutions at home and abroad. And they think that it would reduce the cost of the transformation of the system with opportunistic or free-riding ideas and behaviors. And they would never know that unrealistic systems are difficult to play the effectiveness. And even, these systems would produce negative effects such as obstruction or misleading. For example, in the construction of teaching system of internationalized courses, the first-class colleges and universities in China have relatively mature theoretical foundation and practical experience. After years of international practice, they have achieved satisfactory results. Many other colleges and universities would think that this kind of curriculum system has versatility, and they can borrow it as the standard of the construction of curriculum system in the internationalization of their universities. However, the first-class colleges and universities have solid foundation in the aspects of teacher resources and curriculum resources supply, which is unmatched by other colleges and universities. It is obviously not necessarily suitable for the construction of our international curriculum system. In addition, many colleges and universities have obturation in the concept of running a school. There is no special organization that promotes the internationalization development. And it also lacks necessary policy support and institutional incentives, teaching management systems related to international development, and incentive policies of the researches. And the system of personnel and financial management is relatively undeveloped or even missing. There are also the defects of arbitrariness. It lacks long-term stability. And then, it can't provide long-term, stable and effective guidance and promotion for the internationalization of teachers. As Taylor argues, HRM strategies in the colleges and universities should be closely related to the international development of the teachers. And then, it could promote teacher-led participation in internationalization construction [15].

And many universities lack the strategic plan for the internationalization work. And the strategic plan is only a symbol. The strategic plan can't be implemented and has not been implemented through effective methods [16]. Childress, at George Washington University in the United States believes that the internationalization strategy of the universities generally falls into three stages. First, it is the "institutional strategic plan" of type A. That is, the universities only have the planning and presentation of international strategy. Second, it is "clear planning of the document" of type B. The universities clearly state the international tasks and goals. Third, it is "departmental strategy" of type C. The internationalization will be implemented in teaching and academic units at the grassroots level, such as colleges and schools in the universities, and relevant offices and personnel of the faculties [17]. From the perspective of the implementation, the university internationalization strategy should be implemented in three levels step by step. Especially, the departmental strategy is a direct guide for the internationalization of teachers. And some studies have found that the level of internationalization of colleges and universities has close relationship with the middle school leaders such as the president [18]. At present, most colleges and universities in China at most remain in the stage of "institutional strategic planning". And they have neglected "clear document planning" and "departmental strategies" that are more conducive to the implementation and guidance. In addition, in the process of building various strategic planning, it has rarely absorbed the participation of front-line teachers. And then, the strategic planning and design is difficult to obtain common understanding and consensus among teachers.

\section{The Deficiency of Motivation: the Teachers' Willingness of Participation Is Flat}

The theoretical framework model of the development of university teachers proposed by Bergquist, Phillips and Gaff, respectively takes teachers' attitudes towards teaching and new approaches as key elements [19]. That is to say, the teacher's attitude is the basic condition for the development of teachers. Childress's research holds that attitude is an important factor for teachers to participate in the internationalization [20]. Liu Chunxiang's empirical investigation of 27 universities in Shanghai shows that attitudes have a significant impact on the foreign teaching of university teachers [21]. Thus, teachers' participating willingness has a very important influence on the internationalization of teachers. However, some researches show that, with the promotion of the development of the internationalization, university teachers in China more or less integrate the viewpoint and content of internationalization into the curriculum system and teaching method. However, the internationalization hasn't been really implemented in terms of curriculum design and reform [14]. Weldon's research suggests that teachers do not know what to do and how to do it in university internationalization. Even if they know how to do it, they also have various attitudes toward the internationalization [22]. Teachers' willingness is determined directly by the motivation. Due to various obstacles in the development of the internationalization of teachers at the organizational level, as well as the blind cognition of their own career development and living burden, young teachers are less motivated in their internationalization. And the sense of responsibility and 
sense of mission is also relatively weak. And then, teachers' willingness to participate in the internationalization is flat. It determines that teachers seldom take the initiative to participate in the internationalization construction, especially in the construction of internationalization in China. It shows negative treatment of several aspects, such as the integration of internationalized views and methods in teaching, the utilization of original foreign textbooks, the practical application of bilingual teaching, the international cooperation in scientific research, the creation of international influence and so on. At the same time, due to the pressure imposed by the university seeking for the rapid development of internationalization, the teachers in vocational development is being put under the pressure. As a result, young teachers are passive in the construction of the internationalization. And even, they have the attitude of rebellions, which severely affects internationalization quality and level.

\section{E. The Burden of Learning Costs: Teachers' Knowledge Base of Internationalization Is Weak}

In 1981, Elbaz firstly studied the teacher's practical knowledge. He believed that teachers had unique and highly experienced and individualized knowledge that is characterized by the practical environment and the social environment [23]. This type of knowledge, relating to all types of students, classrooms, schools, societies and disciplines, has been integrated into teachers' personal values [24]. Golombek classifies teachers' practical knowledge into four categories: self-knowledge, subject content knowledge, pedagogy knowledge and situational knowledge [25]. On this basis, Chen Xiangming, a Chinese scholar, further supplemented that the teaching practice could be divided into six categories: education belief, self-knowledge, interpersonal knowledge, situational knowledge, strategic knowledge and critical reflection knowledge [26]. The author believes that in addition to the six types of knowledge put forward by scholar Chen Xiangming, the practical knowledge of teachers should also include foreign language knowledge and intercultural knowledge in the process of the internationalization. Among them, what the most important in the internationalization are foreign language knowledge that determines communication skills, cross-cultural knowledge that determines cultural inclusion, interpersonal knowledge that determines the effectiveness of cooperation, and self-knowledge that determines self-knowledge. With rich international practical knowledge, teachers can take the most appropriate approach from a variety of perspectives in the practical operations of the internationalized to grasp the overall problem and understand a variety of possibilities. And then, they can quickly and accurately make decisionmaking to the development of international. Obviously, international practical knowledge is a system of rich knowledge, which virtually increases the cost of learning. Some knowledge even scares teachers off it. And then, teachers would lose their opportunities for the international development. In contrast, foreign language education in China is more developed. And various platforms including professional title assessment and foreign language training are constantly strengthening the teachers' mastery of foreign language knowledge. Even so, the foreign language knowledge acquired by teachers stays in the category of theoretical knowledge of the subject rather than practical foreign language knowledge. And practical knowledge can only be effectively trained in the actual situation. The practical knowledge of foreign language has already been this case. And we should pay more cost to carry out effective learning of other knowledge (such as cross-cultural knowledge, communication knowledge, etc.). Thus, it could help the international development. However, most of this knowledge relies on contextual training. At present, the teachers lack this training. Teachers have a weak foundation of international practical knowledge.

\section{THE COUNTERMEASURE OF INTERNATIONAL DEVELOPMENT OF YOUNG TEACHERS IN COLLEGES AND UNIVERSITIES}

\section{A. The Function of Science Positioning Colleges and Universities in the International Development of Young Teachers}

Teachers are the core and leaders in the internationalization development of colleges and universities. The internationalization of teachers depends on the functions of colleges and universities. If colleges and universities can play their functions in the internationalization of teachers, it will greatly promote the development of internationalization of teachers.

1) Colleges and universities should become the organizers of the internationalization development of young teachers rather than the dominant leaders: On the one hand, colleges and universities are required to provide teachers with relevant resources such as financial resources, institutional resources, teaching and research resources for international development. And then, the teachers can obtain sustained resources in the construction of the internationalization (especially in domestic and international practice). On the other hand, colleges and universities should take the initiative to seek opportunities for cooperation with first-class institutions both at home and abroad, actively analyze the situation and opportunities in the world and create conditions for the internationalization of teachers. Internally, various incentive mechanisms and measures should be developed to stimulate teachers' active participation in internationalization. And from the management, teachers can actively participate in the international construction. However, it should be noted that colleges and universities should not become the dominant leaders of the internationalization of teachers. And they also should not control teachers' internationalization through institutional pressure. Under the framework of the macroframework, colleges and universities should give teachers full freedom to find suitable international development paths according to their own conditions.

2) Colleges and universities should become leaders of the internationalization of young teachers rather than 
decision-makers: The so-called leader means that colleges and universities play a guiding role and a driving force in the internationalization of teachers, and play a leading role in the formulation of relevant management systems. However, colleges and universities can't become decisionmakers. That is to say, colleges and universities would provide the advantages of their resources and conditions, and the suggestions for the internationalization of teachers with the development needs of colleges and universities. And the colleges and universities can't decide whether teachers choose their suggestions. In the formulation the relevant system, colleges and universities are the leaders, and teachers' opinions and suggestions should also be fully heard. Then, the system can reach a broad consensus among teachers.

3) Colleges and universities should become the diggers of the potential of internationalization of young teachers rather than the decider of ability: Colleges and universities should conscientiously sort out and make dynamic analysis of young teachers of the whole universities. If necessary, the colleges and universities should develop a deep analysis on the ability and potential of young teachers by means of speculation, prediction and other computational methods. The colleges and universities should grasp the explicit and potential capacity of the system and level of the young teachers. And then, the colleges and universities may provide suggestions for appropriate international development of the teachers. However, colleges and universities can't subjectively judge teachers' abilities. Also, they can't autonomously define teachers' subjectivity in a subjective way. They should understand teachers' abilities in a deep and predictive way.

\section{B. To Play the Leading Role of Young Teacher in University Internationalization}

Teachers should take the initiative to participate in the construction of the internationalization. And it should become the ultimate goal of international management of colleges and universities. To play the leading role of teachers is also a significant difference between the internationalization of teachers and the internationalization of faculty. Under the premise of combining their own needs with the development of colleges and universities, teachers need to play a leading role in internationalization based on their own academic career and resources. On the one hand, this dominant role is determined by teachers' own development concept and demand. More importantly, colleges and universities can promote the realization through some incentives, subsidies and policy preferences. For example, if faculty training programs are set up, teachers should be encouraged to understand and participate in curriculum design, reform and training programs based on their knowledge of international related courses. Young teachers are active in thinking. They are good at capturing the latest developments in the field at home and abroad. Colleges and universities should make full use of these specialties to inspire teachers to actively offer advice and suggestions in the construction of an international curriculum system.

\section{To Establish and Improve the Management System of International Development of Young Teachers}

The management system of international development of teachers should mainly include human resources management system of the teachers, curriculum management system and scientific research management system. Through the establishment of these systems, on the one hand, teachers can be encouraged to take part in the internationalization of universities actively. On the other hand, the colleges and universities should provide macro-framework regulation for teachers' internationalization. And then, teachers' international development should adapt to the development of teachers. In addition, colleges and universities should formulate and perfect short-term, medium-term and longterm strategic plan for the internationalization development. With the guidance of strategic planning, colleges and universities should make a choice and focus on the implementation of the plan step by step. In the process, it should focus on the main consciousness of the colleges and universities. The formulation of the strategic plan should be specific and detailed. Also, it should meet the needs of the actual development of the universities and the academic career development of teachers. At the same time, in order to implement and operate the plan easily, colleges and universities should carry out the concept of international development throughout the university through the improvement of measures and systems in terms of policies, funds and assessment. It should emphasize the subjective consciousness, and give the department greater autonomy to make the decision. Then, it would stimulate the enthusiasm and initiative of teachers in the internationalization development. At the same time, colleges and universities should set up an international promotion mechanism with the departments as the platform, the universities as the guidance of the framework, teachers as the main body. And the internationalization of teachers and the degree of international development of teachers should be the assessment indicators for the departments. Not only that, colleges and universities should strive to create campus atmosphere for the internationalization development of teachers. Through strong campus culture, it can create international university spirit, learning style and teaching style. Then, the concept and value of internationalization are deeply integrated into the teacher's value system and academic career planning.

\section{To Develop International Organizations of Young Teachers}

Organizations are the physical guarantee for the internationalization of teachers to operate effectively and move forward. At present, the vast majority of colleges and universities have established relevant organizations for international development. However, they have not paid much attention to these organizations. Most of their members are part-time duty personnel. And these organizations are basically university-level agencies such as the foreign affairs department, International exchange and cooperation center or 
international colleges. The international management of teachers in the whole university depends on this. This is obviously not only difficult to get along with, but also difficult to effectively perform their functions due to the complexity of international affairs. The most effective approach is that colleges and universities should establish university-level and college-level learning institutions. The university-level institutions should be responsible for the macro-level guidance, and college-level institutions should implement and promote the international development from a micro perspective.

\section{E. To Strengthen Academic Education of Teachers}

Through advocacy, guidance and establishment of systems and measures, we should cultivate the teachers' sense of ownership in internationalization development. And then, they will have profound understanding of the important role of the development of university in their personal development. Also, they should strengthen their ideological awareness and education in the process of the internationalization. At the same time, the teachers should keep an eye on the world, track the development of scientific research and teaching in foreign countries, and win the support of foreign teaching and scientific research resources. We should provide a platform for the development of international cooperation. Through inter-school cooperation, tutorial system and visiting first-class colleges and universities, the teachers should strengthen awareness of international development, enhance teachers' academic professional ability and take the initiative to fight for resources and carry out international cooperation. For example, colleges and universities can fully seek the opinions and suggestions of teachers. Then, they also should introduce foreign high-quality curriculum system (including curriculum and supporting materials), curriculum management system and advanced teaching methods.

\section{CONCLUSION}

This study overlooks the obstacles of the international development of young teachers in universities from a macro perspective and puts forward corresponding development strategies. There are three main contributions in this study. First, it puts forward that "domestic internationalization" of native teachers should become the core of the internationalization development of university teachers. Second, the author sorts out the five major obstacles of the internationalization development of university teachers from the perspective of top-level design. And this paper attempts to find out the main reason of the obstacles of the internationalization of university teachers from the perspective of ideology and values. Third, the author gives five countermeasures of internationalization development of college teachers from the perspective of bottom support. And the author tries to overcome the main obstacles in the internationalization of university teachers with pragmatic measures. However, the problem of the internationalization of teachers is a complicated issue. There are some shortcomings in the study of this issue. First, there is no empirical research on the internationalization of young teachers, which lacks the support of certain data. It is suggested that the scholars should make the researches on the concept of teacher internationalization, the demand of career development and other problems from the perspective of sociology, psychology and management. And they also can carry out investigation and analysis. Second, it has no special and meticulous research to analyze the opportunities, threats, advantages and disadvantages of teacher internationalization from the perspective of external environment and internal management. It is suggested that the follow-up study can analyze the internal and external environment of the internationalization of teachers by taking the SWOT model as the basic analysis method. Of course, the above insufficiency is the challenge of the comprehensiveness of this study. And it doesn't affect the accuracy and scientificness of the conclusions of this study.

\section{REFERENCES}

[1] China Science Daily. Some understandings on the internationalization. [2017-01-14]. http://news.sciencenet.cn/htmlnews/2016/10/358785.shtm.

[2] Wang Xia. Teachers' participation in the internationalization of college courses [J]. Journal of Higher Education, 2010 (3): 64-70.

[3] PETERSON P M. The centrality of faculty to a more globally oriented campus [EB/OL]. [2017-01-08] http://www.acenet.eduAMTemplate.cfmSection=ciinetworks\&Templ ate $=$ CMContentDisplay.cfm $\&$ ContentFileID $=3958$.

[4] Li Xiaohui. Study on the internationalization construction of teaching staff in local colleges in Jiangsu Province [J]. China Adult Education, 2016(13): 122-125.

[5] Jiang Yumei, Liu Qin. Research on the benefit of teachers studying abroad in the international context of higher education $[\mathrm{J}]$. Open Education Research, 2015(1):62-70.

[6] Li Bihong. Academic internationalization: Based on the perspective of teachers' development [J]. Open Education Research, 2015, 4 (21): 60-67.

[7] Philip Warwick, Yvonne J. Moogan. A comparative study of perceptions of internationalisation strategies in UK universities[J]. Compare: A Journal of Comparative and International Education, 2013, 43(1): 102-123.

[8] Rudzki, R. The Application of a Strategic Management Model to the Internationalisation of Higher Education [J]. Higher Education, 1995, 29 (4): 421-441.

[9] McNicholl, Y., S Burney, and A. Luff. Enhancing faculty culture to meet student needs: internationalising the curriculum [C]. Australian Universities Quality Agency Conference, Canberra, 2008: 9-11.

[10] Harari, M . Internationalizing the curriculum and the campus: Guidelines for AASCU Institutions[M].Washington, DC: American Association of State Colleges and Universities, 1981: 29.

[11] Sorcinelli, M.d, Austin, A.E., Eddy, P.L.\% Beach, A.L.Creating the future of faculty development: Learning from the past, understanding the present $[\mathrm{M}]$. Bolton, M A: Anker Publishing Company, Inc, 2006:2-5,157.

[12] Finkelstein, M.J.,Walker, E.\& Chen, R. The American faculty in an age of globalization: predictors of internationalization of research content and professional networks[J].Higher Education, 2013,66(3):32-340.

[13] Knight. Liu Dongfeng translation. Higher education in the torrent [M] Beijing: Peking University Press, 2011: 221.

[14] Li Bihong, Tu Yangjun. On the limited participation of university teachers in the internationalization of higher education $[\mathrm{J}]$. Fudan Education Forum, 2012(6): 54-58. 
[15] Taylor, J. Towards a strategy for internationalisation: lessons and practice from four universities[J]. Journal of Studies in International Education, 2004,8 (2): 149-171.

[16] Bartell, M. Internationalisation of universities: a culture based framework [J]. Higher Education, 2003, 45 (1): 43-70.

[17] Lisa K.Childress. Internationalization plans for higher education institutions [J]. Journal of Studies in International Education, 2009, 13(03): 289-309.

[18] China Science Daily. The internationalization of colleges and universities: International thinking behind the ranking list. [2017-0114]. http://news.sciencenet.cn/htmlnews/2013/11/285607.shtm

[19] Lin Jie, Li Ling. Three theoretical models for the development of American university teachers [J]. Modern University Education, 2007 (1): 62-66.

[20] Childress, L.K. The twenty-first century university: Developing faculty engagement in internationalization $[\mathrm{M}]$. Peter Lang, 2010:3334.

[21] Liu Chunxiang, Zhao Zhongjian. The effect of overseas training of university teachers from the perspective of curriculum internationalization-An empirical investigation based on 27 universities in Shanghai [J]. Teacher Education Research, 2014 (2): 108-112.

[22] Weldon, P., J. Rexhepi, C. Chang,et al. Globalisation and Higher Education in Southern California:Views from the Professoriate[J].Compare,2011,41 (1): 5-20.

[23] Elbaz. F. The teacher's "practical knowledge": Report of a case study[J].Curriculum Inquiry, 1981(11):43-71.

[24] Elbaz. F. Teacher Thinking: A Study of Practical Knowledge[M].London: Croom Helm,1983.

[25] Golombek, P. A study of language teachers' personal practical knowledge[J].TESOL Quarterly, 1998(3):447-464.

[26] Chen Xiangming. Discussion on the components of teachers' practical knowledge [J]. Educational Research, 1999 (10): 66-73. 